\title{
Gestão eficiente na saúde pública brasileira
}

\author{
Mariana Pereira DERMINDO(1)
}

${ }^{(1)}$ Faculdade de Saúde Pública, Universidade de São Paulo - USP, São Paulo, SP, Brasil.

Recebido: 28 jan 2019 Aceito: 10 fev 2019

Autor de correspondência: marianadermindo@gmail.com

Conflito de interesses: Os autores declaram não haver nenhum interesse profissional ou pessoal que possa gerar conflito de interesses em relação a este manuscrito.

\section{Resumo}

Considerada uma prática administrativa, a gestão em saúde busca, através da melhor combinação dos recursos disponíveis, aprimorar o funcionamento das organizações através de ações eficientes, eficazes e efetivas que permitam que a instituição alcance seu objetivo. Diante das crises financeira e social enfrentadas pelos Estados, somadas às transições demográfica, tecnológica e epidemiológica que pressionam os orçamentos, os governos, na tentativa de aumentar a eficiência e a satisfação do usuário, tem buscado novas estratégias de cobertura e formas mais versáteis de gestão e financiamento. Concebida como a indissociação do uso racional e ótimo dos meios e a satisfatoriedade dos resultados, a eficiência passou a ser palavra de ordem em meados dos anos 1980, após a introdução de ferramentas e técnicas provindas da iniciativa privada na tentativa de modernizar a gestão do setor público; essas mudanças ficaram conhecidas como nova administração pública ou gerencialismo. Há na literatura questionamentos acerca dessa nova administração pública, devido ao entendimento de que não houve nenhum estímulo ou exigência pelo Estado frente aos seus parceiros históricos na prestação de serviços de saúde. Há ainda dúvidas sobre a necessidade da gestão pública basear-se nos mesmos moldes da gestão empresarial, pois, ao que parece, a adoção dessa nova metodologia traz um esvaziamento da dimensão sociopolítica da gestão, afigurando-se como pouco democrática. A eficiência na gestão é essencial para que não sejam negados tratamentos por falta de recursos e para evitar desperdício com materiais, exames ou medicamentos. Quando há falhas na entrega do serviço em saúde, outros setores da sociedade são prejudicados; além disso, cuidados ineficientes reduzem a vontade social de contribuição e luta pela consolidação do Sistema Único de Saúde - SUS. O presente trabalho aborda o conceito de eficiência na gestão da saúde pública brasileira por se pautar na compreensão de que a gestão eficiente pode promover uma saúde mais equânime. Objetivo: analisar o uso do conceito de eficiência na gestão dos serviços de saúde do SUS. Metodologia: partindo do questionamento sobre o que há disponível na literatura sobre eficiência de gestão em serviços públicos de saúde, considerouse como contexto de estudo a gestão em saúde pública, o fenômeno identificado foi a eficiência de gestão e os serviços públicos de saúde foram tomados como população. Com o intuito de definir os assuntos e recuperar artigos de interesse utilizou-se uma terminologia padronizada com base nos Descritores em Ciências da Saúde - DeCS. Através da estratégica de busca ["administracao de servicos de saude" $O R$ "administracao em saude publica" $O R$ "administracao hospitalar" $O R$ 
"gestao de recursos" $O R$ "gestao em saude" $A N D$ "indicadores de gestao" $O R$ "governanca clinica" $O R$ "modernizacao do setor publico" $O R$ "eficiencia" $A N D$ "saude publica" $O R$ "hospitais municipais" $O R$ "hospitais publicos" $O R$ "centros de saude" $O R$ "servicos de saude" $O R$ "parcerias publico-privadas" $O R$ "pesquisa em sistemas de saude publica"] nas bases de dados LILACS e SciELO, foi realizada uma revisão integrativa da literatura de artigos publicados em periódicos nacionais e internacionais. Foram adotados os seguintes critérios de inclusão: artigos que tratassem da eficiência na gestão de serviços de saúde do SUS, que fossem estudos de caso ou relatos de experiências e que possuíssem texto completo disponível. Resultados: foram encontrados 89 trabalhos, desses 74 na base LILACS e 15 na base SciELO, e após a retirada de duplicatas restaram 75. Com a aplicação dos critérios de inclusão e exclusão obteve-se 13 artigos. A Organização Mundial da Saúde - OMS sugere que, independentemente de seu desenvolvimento econômico, os países ou regiões devem tomar medidas para aumentar a eficiência dos serviços de saúde, através de uma avaliação local dos processos envolvidos. Observa-se em todos os artigos um cuidado dos autores em compreenderem quais fatores incentivam ou restringem a eficiência na gestão dos serviços públicos de saúde. Os estudos se dedicaram, principalmente, à análise das estruturas de gestão de hospitais e de redes municipais de saúde. As metodologias foram bastante variadas: estudos comparativos de indicadores de estrutura e indicadores de resultados; grupos focais com gestores; grupos de trabalho com a equipe gestora e os centros assistenciais; análise de dados quantitativos em uma determinada série histórica. Em todos os trabalhos, a eficiência foi apreendida como um esforço dos gestores em realizar suas atribuições com diligência e busca de resultados positivos para o serviço, no que tange a aplicação dos recursos financeiros, e satisfatoriedade na entrega dos serviços necessários à comunidade. Ou seja, devido a escassez de verba para investimentos, a gestão eficiente de serviços públicos de saúde deveria maximizar os resultados obtidos com um dado nível de recursos ou minimizar os recursos necessários para obter determinado resultado. Apesar de apontarem para a mesma definição do termo, os autores divergiram sobre o modo como a eficiência pode ser alcançada e/ou analisada. A implantação de serviços de tecnologia para controle dos custos e organização das informações foram apontadas como essenciais para que o gestor tenha recursos suficientes para uma tomada de decisão satisfatória. Outros estudos apontaram que o processo de descentralização, e a criação de novos hospitais e laboratórios, por exemplo, tem levado a um processo de ineficiência alocativa, já que alguns serviços tem sua qualidade relacionada a uma significativa base quantitativa. Seguindo uma linha de pensamento mais crítico, apenas a análise de avaliações econômicas ou comparação de indicadores não garantirão uma gestão eficiente, essa dar-se-á com a valorização de fatores basilares que se referem às tecnologias relacionais e ao fortalecimento da rede. Alguns autores propuseram ainda um olhar mais atento às influências políticas, especialmente, na definição de prioridades e alocação de recursos, por entenderem que os aspectos legais, normas e cultura 
do contexto institucional podem ser fatores decisivos para o alcance da eficiência nos serviços de saúde. Considerações finais: a presente pesquisa encontra-se andamento, no entanto, os resultados preliminares corroboram a utilização do termo eficiência ao que se refere a gestão dos serviços públicos de saúde como o uso otimizado dos recursos financeiros para a entrega de serviços satisfatórios para a comunidade.

Descritores: Gestão em Saúde. Eficiência. Saúde Pública. 